\title{
Determinants of Market Participation and Supply of Beef Cattle Value Chain in Konso District, Southern Nations, Nationalities and Peoples' Region, Ethiopia
}

\author{
Gezehagn Gesese $^{1^{*}} \quad$ Teshale Woldeamanueal $^{1} \quad$ Belayneh Legesse $^{2}$ \\ 1.Hawassa University, Wondo Genet College of Forestry and Natural Resource, Natural Resource Economics \\ and Policy Department. P.O.Box 128, Shashemene, Ethiopia \\ 2.Haramaya University, College of Agriculture and Environmental science, Agricultural Economics and \\ Agribusiness Department, Agribusiness and Value Chain Management Program P.O.Box 138, Dire Dawa, \\ Ethiopia
}

\begin{abstract}
Beef cattle value addition linkage system has not yet been systematically studied and documented in the study area. This study is therefore aimed at analyzing the major determinants of market participation and supply of beef cattle value chain using both primary and secondary data. The primary data were collected from producers, middle men, traders and consumers. Whereas, the secondary data were collected from different Central Statistical Agencies and different government offices. The Heckman two stage sample selection model was employed and the result shows that market participation in beef cattle was positively affected by sex, age, household size, access to veterinary service, distance of feed source, beef cattle body condition and access to credit. On the other hand, quantity of the beef cattle supplied was affected negatively by access to veterinary service, distance from feed source, market distance and access to credit while household income affected it positively. Therefore, policy aiming at increasing access to modern inputs and market, developing and improving infrastructure and create awareness about how to use available resources intensively. Control of informal, illegal and expired animal drugs entrance in to the district by responsible agents or experts should be in place. Also, making strong visit, follow up and creation of awareness after credit provision should be done.
\end{abstract}

Keywords: Value chain, Actors, Heckman two stage model, Beef cattle

DOI: $10.7176 / \mathrm{FSQM} / 83-01$

\section{INTRODUCTION}

Livestock in Ethiopia perform important functions in the livelihoods of farmers, pastoralists and agro-pastoralists. They are sources of food (meat and milk products), services (transport and traction), cash income, as drought animals, manure (for soil fertility management and fuel), and serve as store of wealth. The subsector also provides year-round employment for a significant part of the rural population, which would perhaps remain unemployed otherwise (ESAP 2002). Therefore, cattle production in Ethiopia is an integral part of the mixed farming, agro-pastoral and pastoral production systems.

According to Teshager et.al, (2013), cattle fattening practices in Ethiopia is categorized into three major fattening systems: traditional system, by product-based system and Hararghe fattening system. Cattle are only sold or slaughtered at an old age, or in case of urgent need. If slaughtered, the animal provides the family with meat and income from hides and skins. With this immense and potentially productive resource, with such influence on household incomes as well as the national economy, it is imperative for the Ethiopians to maximize the economic value of their animal assets, including use of the animal for value added products. Yet, by most economic metrics, this is not still well developed in most poor countries including Ethiopia. Animals are not managed for high off-take, or to maximize their value for meat production (Jabbar and Gezahegn 2003).

This study, therefore, was initiated to examine the major determinants of market participation and supply of beef cattle value chain in the contextual setting of the district.

\section{METHODOLOGY}

\subsection{Description of the study area}

This study was carried out in Konso-District, located about $600 \mathrm{~km}$ south of Addis Ababa Geographically, it is located at $5^{\circ} 10^{\prime}-5^{\circ} 40^{\prime} \mathrm{N}$ latitude and $37^{\circ} 00^{\prime}-37^{\circ} 40^{\prime} \mathrm{E}$ longitude in the circle of the Great Rift Valley. The district has a total land area of 2,274 sq. $\mathrm{km}$.

The altitude of Konso varies between $500 \mathrm{~m}$. and $2000 \mathrm{~m}$. a.s.l. (Beshah, 2003). The main agro-ecological divisions of Konso is $70 \%$ arid (Kola) and 30\% tropical sub-humid (Weina Dega). The mean annual temperature of the District ranges between 17.6 and $27.50^{\circ} \mathrm{C}$; which is mostly hot and warm. The average total annual rainfall is $550 \mathrm{~mm}$ (Cheung, 2008). The soil of the area is 35\% sandy, 30\% clay and the rest, 35\% loamy soil. The District has a population of 235,087 persons (CSA, 2007) (figure 1). 


\subsection{Data type and analysis}

Both primary and secondary data sources were used. Primary data was collected from sampled beef cattle value chain actors. Secondary data was collected from published materials and district administration. Primary data was collected using household survey, focus group discussions, and key informant interviews. Focus group discussions were conducted with different groups from each kebele using checklist prepared for this purpose. The group consisted of men, women, youth, elders and village leaders.

For this study, a three-stage sampling procedure was employed to select beef cattle suppliers in the kebeles. In the first stage, Konso district was selected purposely as it has a huge potential for beef cattle production compared to other districts. In the second stage, four Sample kebeles were selected out of the 43 kebeles in the District purposefully based on their potential of market participation and market supply of beef cattle and their proximity to the local market. Finally, sample households were selected randomly with probability proportional to size from sample kebeles after stratifying households by the sex of the heads.

The determination of sample size was resolved using Yamane (1967), simplified formula to calculate the sample size with the desired confidence level of $95 \%$.

Where:

$$
n=\frac{N}{1+N(e)^{2}}
$$

$\mathrm{n}=$ actual sample size;

$\mathrm{N}=$ total number of $\mathrm{HHs}$ in the four kebeles;

$\mathrm{e}=$ margin of errors at $8 \%$ (the desired level of precision, $\mathrm{e}=0.08$ ).

For data analysis descriptive statistics such as percentages, frequencies and means were presented in the form of tables and figures. The Hackman's sample selection model where a probit model for the participation or "selection" equation was estimated and an OLS regression model which is corrected for selectivity bias was specified to account for the level of the amount marketed was estimated.

\section{Probit model;}

$Y_{i}=\beta_{i} x_{i}+u_{i} \quad i=1,2,3 \ldots \mathrm{n}$

Where; $Y_{i}$ is a dummy variable indicating the market participation that is $Y_{i}=1$, if $Y_{i}>0 \quad$ otherwise, $Y_{i}=$ $0, \beta_{i}{ }^{\prime} s$ is unknown parameters to be estimated, $x_{i}{ }^{\prime} s$ are variables determining participation and $u_{i}$ is the random error term.

\section{OLS model;}

Here an estimate of the inverse Mill's Ratio, denoting $\lambda_{i}$, as an additional regressor

$$
Z_{i}=\beta_{o}+\beta_{i} x_{i}+\mu \lambda_{i}+\varepsilon_{i} \quad i=1,2,3 \ldots \mathrm{n}
$$

Where: is the volume of supply by sample households

$Z_{i}:$ are the explanatory variables determining quantity supplied

$\beta_{i}$ : is unknown parameter to be estimated in the quantity supplied function

$\beta_{o: \text { is an intercept term }}$

$\mu$ : is a parameter that shows the impact of participation on the quantity supply and $\mathcal{E}_{i}:$ is an error term.

Variance Inflation Factors (VIF $\left(x_{j}\right)$ ) technique was employed to detect the problem of multicollinearity among continuous variables. Those explanatory variables with VIF $>10$ were excluded from the regression analysis (Maddala, 1988).

$$
\operatorname{VIF}\left(x_{j}\right)=\left(1-R_{j}^{2}\right)^{-1}
$$

Where, $\mathrm{R}_{\mathrm{j}}$ is the coefficient of multiple determination when the variable $x_{j}$ is regressed on other explanatory variables.

To detect the problem, the contingency coefficients were computed from the survey data, and contingency coefficient greater than 0.75 is an indication of existence of multicollinearity among qualitative variables.

$$
C C=\sqrt{\frac{x^{2}}{N+x^{2}}}
$$

Where, $\mathrm{CC}$ is contingency coefficient, $x^{2}$ is chi-square and $\mathrm{N}$ is total sample size. 


\section{RESULTS AND DISSCUTION}

\subsection{Socio-economic Characteristics of Sample Beef Cattle Producers}

The average age of the overall sample heads of households was 39.35 year with minimum and maximum age of 20 and 63 years, respectively. Fifty percent of the sample households are followers of Protestant Christianity. The remaining $17.76 \%$ and $32.24 \%$ are followers of Orthodox Christianity and believers in cultural religion (Ata), respectively. Regarding their marital status, about $93.42 \%$ (i.e. 142 sample producers), $1.97 \%$ and $4.61 \%$ out of the total households were married, single and widowed, respectively (table 1).

The majority of the sample household heads (i.e. $56.58 \%$ which was 86 sample respondents) have no educational background. The remaining $13.81 \%, 21.06 \%, 2.63 \%$ and $5.92 \%$ of the sample household heads respondents followed grade levels 2-4, 5-8, 9-10 and 11-12 and above, respectively (table 1).

\subsection{Econometric Analysis Results}

Here, the likelihood function is significant (Wald $\chi^{2}=9851.70$ with $\mathrm{P}<0.0000$ ) showing strong explanatory powers. Similarly, the coefficient of the Mill's ratio is found to be significant $(\mathrm{P}<0.076)$ which indicate presence of self-selection and hence justifying the appropriateness of using Heckman's two-stage model. In addition, multicollinearity and other econometric test are made for the independent variables using VIF and coefficient of contingency, respectively. The result has shown that there is no multicollinearity problem among or between the variables.

\section{Determinants of beef cattle market participation decision}

Out of the 13 variables expected to affect probability of market participation of the sample household, seven variables are found to significantly explain the probability of participation in the beef cattle market. Sex of the household head (SEXHH), age of the household head (AGEHH), household size (HHSZ), distance from farmland to provide feed (DIFESOU), veterinary service access (VETSERV), body condition of beef cattle (CATBC) and access to credit service (ACRED) have positively and significantly affected market participation of the sampled households. However, the coefficients of the independent variables experience in beef production, education level, land size, household income, total number of cattle owned and distance to the nearest market were found to be insignificant.

The result showed that being female household head increases the probability of market participation of the sample participant by $12.123 \%$. As age of the producer increase by one-year probability of beef cattle market participation of producers increases by $0.49 \%$ because as household head matures the more, they are able to make decision. Marginal effect of household size increases probability of the market participant in beef cattle by $0.77 \%$ at $10 \%$ level of significance. Moreover, the sample producers start receiving veterinary service for beef cattle their probability of participation in markets increases by an amount of $17 \%$. Similarly, addition of one more kilometre on distance of crop residue from beef cattle increases participation of the sample producers in beef cattle markets by $0.75 \%$. Good body condition of beef cattle also leads to a better probability of producer's participation in beef cattle markets by $20 \%$ because beef cattle with good body condition are more demanded by buyers and at good market price than others which have poor body condition/appearance. At the end, having access to veterinary service in beef cattle production increases the probability of participation of producers in beef cattle markets by $10.7 \%$ (table 2 ).

\section{Determinants of amount of beef cattle supplied to the markets}

This section shows OLS estimation result of Heckman two stage model. It incorporates inverse Mills ratio. Inverse Mills ratio (lambda) is found to affect amount of beef cattle supply to markets significantly. This implies covariates that condition the amount of beef cattle sold operate conditional on the probability to participate in beef cattle markets as a seller. Remarkably, four of the explanatory variables and constant term have significantly explained the quantity supply of beef cattle to markets. These variables are access to veterinary service, household income, distance from nearest market and access to credit.

Access to veterinary service has an unexpected outcome. As a result, having access to veterinary service reduces the quantity supply of beef cattle to markets by an amount of 2.3 TLU at $1 \%$ level of probability. Addition of one more birr on income of beef cattle producers increases the quantity supply of beef cattle to markets by an amount of 0.002 TLU at $1 \%$ level of probability. A market distance to which the beef cattle are supplied decreases total number of the beef cattle supply to markets by an amount of 0.008 TLU. With respect to existing credit and risk management for the beef cattle value chain very few producers are credit worthy, however, majority of the sample producers' access neither credit nor risk management services (they are risk avert). Moreover, having access to credit reduces supply of beef cattle to the market by an amount of 2.3 TLU at $5 \%$ level of probability ((table 3$)$. 


\section{SUMMARY AND CONCLUSION}

This study is aimed at analyzing beef cattle value chain in Konso district SNNP Region, Ethiopia. Both primary and secondary data sources were used to analyze the value chain. The analysis is made using descriptive statistics and econometric model using STATA software.

Market participation decision and marketed quantity of beef cattle are found to be important elements in beef. Therefore, in identifying determinants that affect both market participation and supplied quantity of beef cattle, Heckman two stage sample selection model was used.

Result of the Heckman two stage sample selection model indicate that participation of sample producers in beef cattle markets is significantly affected by sex of the household head (SEXHH), age of the household head, household size, distance of the beef cattle from crop residue, access to veterinary service, body condition of beef cattle owned and access to credit service. The supplied quantity of beef cattle in to markets is also affected by access to veterinary service, household income, and distance from the nearest market and access to credit significantly.

\section{RECOMMENDATIONS}

The recommendations or policy implications are: -

- It could be better to introduce alternative feed sources to be obtained near the beef cattle production area and create awareness about how to use available resources intensively.

- Control of informal, illegal and expired animal drugs entrance in to the district by responsible agents or experts should be in place.

- Work of creating awareness about the negative impact of traditional way of curing beef cattle and find possibilities either for legal, formal governmental or private veterinary service giving clinics

- Making strong visit, follow up and creation of awareness after credit provision should be done in order to reduce/avoid diversion of credit to other business or issues.

- Government should also create enough financial support to the producers in the form of credit to run and strengthen the beef cattle business appropriately.

\section{REFERENCES}

1. ESAP (Ethiopian Society of Animal Production) (2002). Livestock in Food Security. Roles and Contributions. Proceedings of 9th annual conference of the Ethiopian Society of Animal Production (ESAP) held in Addis Ababa, Ethiopia, August 30-31, 2001. ESAP (Ethiopian Society of Animal Production) 433pp

2. Jabbar, M.A. and A. Gezahegn (2003). Livestock Marketing, Food Security and Related Issues in Ethiopia, A Paper Prepared for the Workshop on 'Towards Sustainable Food Security in Ethiopia: Integrating the Agri-food Chain' held at Ghion Hotel, Addis Ababa, Ethiopia, 15-16.

3. Besha, T (2003). Understanding Farmers Expanding Soil and Water Conservation in KonsoWolaita and Wello, Ethiopia Tropical Resource Management Paper 41 81-116.

4. Cheung, W.H., Senay, G.B., Singh, A (2008). Trends and Spatial Distribution of Annual and Seasonal Rainfall in Ethiopia [online in] www.interscience.wiley.com Communities, SIDA, Nairobi, Kenya

5. CSA (central statistics agency) (2006). The Population and Housing Census of Ethiopia, 2007

6. Pound, B. and Jonfa, E. Cattle in Southern Ethiopia: Participatory studies in Wolaita and Konso woredas FARM-AFRICA WORKING PAPERS No. 3

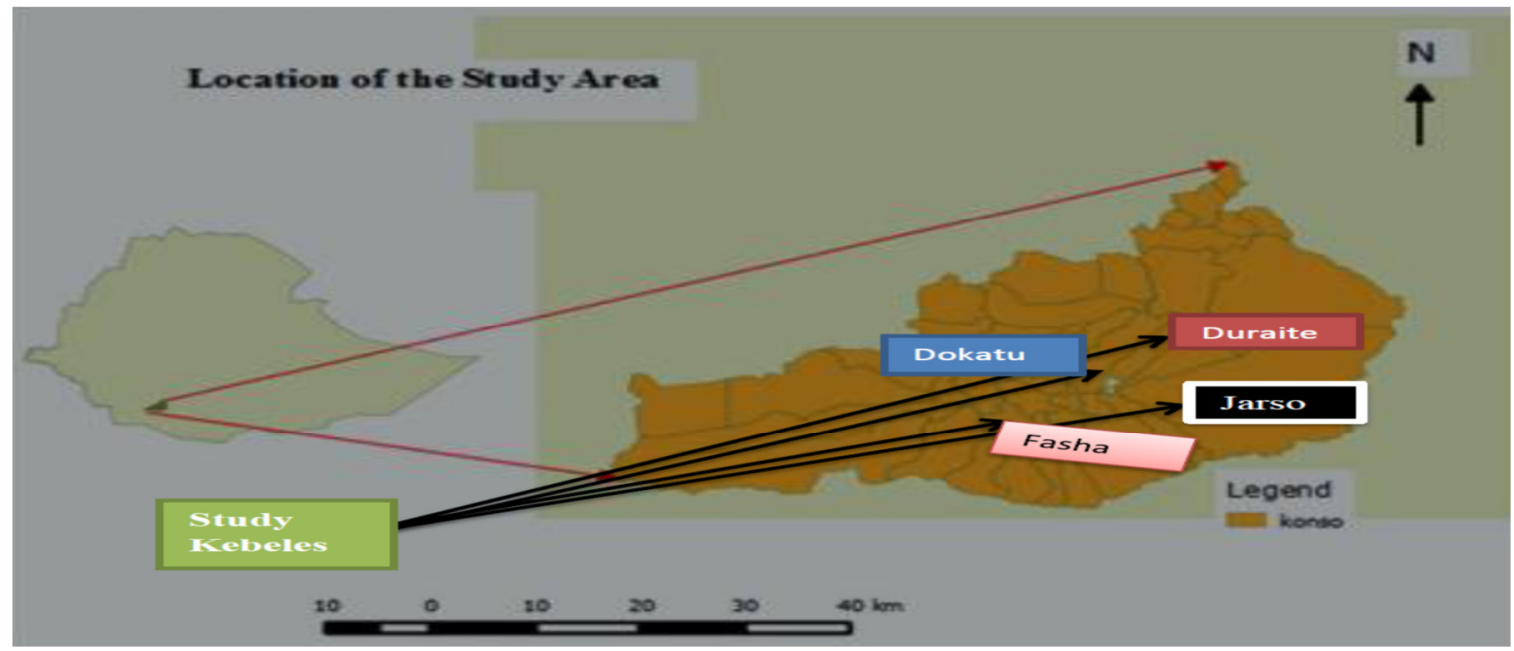

Figure 1: Map of the study area 
Table 1: Summary statistics of the socioeconomic characteristics of beef cattle producers

\begin{tabular}{lllll}
\hline Variables & Mean & Std. Dev. & Min & Max \\
\hline Age of household & 39.35 & 9.19 & 20 & 63 \\
Experience & 10.24 & 7.86 & 0 & 30 \\
Education level & 2.72 & 3.80 & 0 & 15 \\
Household size & 5.32 & 2.63 & 2 & 14 \\
Land size & 1.57 & 2.36 & .01 & 12.5 \\
Distance from feed source & 3.32 & 2.15 & .2 & 12 \\
Household income & 993.67 & 568.108 & 280 & 3200 \\
Cattle size & 9.90 & 10.609 & 0 & 68 \\
Distance from market & 53.34 & 64.58 & 3 & 570 \\
\hline
\end{tabular}

Source: own survey result, 2014/2015

Table 2: Probit result of the market participation

\begin{tabular}{lllllc}
\hline Variables & Coef. & Std. Err. & $\mathrm{Z}$ & $\mathrm{P}>\mathrm{Z}$ & Marginal effect (dy/dx) \\
\hline SEXHH & 0.12 & 0.024 & 4.99 & 0.000 & $0.121^{* * *}$ \\
AGEHH & 0.0047 & 0.0013 & 3.68 & 0.000 & $0.0048^{* * *}$ \\
EXP & -0.0007 & 0.0016 & -0.41 & 0.680 & -0.00067 \\
EDLHH & 0.0009 & 0.0027 & 0.25 & 0.802 & 0.00067 \\
HHSZ & 0.0078 & 0.0039 & 1.93 & 0.054 & $0.0077^{*}$ \\
LANDSIZE & -0.0023 & 0.0040 & -0.61 & 0.541 & -0.0025 \\
VETSERV & 0.17 & 0.03 & 5.62 & 0.000 & $0.17^{* * *}$ \\
DIFESOU & 0.0075 & 0.0042 & 1.77 & 0.076 & $0.0075^{*}$ \\
HHINC & 0.00002 & 0.000017 & 0.88 & 0.379 & 0.000015 \\
CATTSZ & 0.00013 & 0.00095 & 0.11 & 0.911 & 0.0001 \\
CATBC & 0.199 & 0.0329 & 6.09 & 0.000 & $0.200^{* * *}$ \\
DISMAK & 0.0002 & 0.00015 & 1.02 & 0.309 & 0.00015 \\
ACRED & 0.106 & 0.022 & 4.92 & 0.000 & $0.107^{* * *}$ \\
\hline
\end{tabular}

Source; survey result of $2014 / 15$

$* * * \& *$ shows the $1 \%$ and $10 \%$ level of significance respectively.

Number of obs. $=152 \quad$ Censored obs. $=32$ Uncensored obs. $\quad=120$

Wald $\operatorname{chi}^{2}(13)=9851.70$ Prob $>$ chi2 $=0.0000$

Table 3: OLS result of the Heckman two stage model

\begin{tabular}{lllll}
\hline Variables & Coef. & Std. Err. & $\mathbf{Z}$ & $\mathbf{P}>\mathbf{Z}$ \\
\hline SEXHH & 0.24 & 0.64 & 0.38 & 0.706 \\
AGEHH & -0.015 & 0.027 & -0.56 & 0.579 \\
EXP & 0.011 & 0.034 & 0.34 & 0.736 \\
EDLHH & 0.014 & 0.066 & 0.21 & 0.831 \\
HHSZ & 0.2035 & 0.129 & 1.58 & 0.114 \\
LANDSIZE & 0.041 & 0.112 & 0.37 & 0.713 \\
VETSERV & $-2.26 * * *$ & 0.443 & -5.10 & 0.000 \\
DIFESOU & 0.1509 & 0.130 & 1.15 & 0.249 \\
HHINC & $0.0022^{* * *}$ & 0.0009 & 2.61 & 0.009 \\
CATTSZ & 0.047 & 0.041 & 1.14 & 0.255 \\
DISMAK & $-0.0079 * *$ & 0.0039 & -1.98 & 0.048 \\
ACRED & $-2.34^{* *}$ & 0.9296 & -2.51 & 0.012 \\
cons & $5.69^{* * *}$ & 2.128 & 2.67 & 0.008 \\
\hline Lambda & $-0.085^{*}$ & .048 & -1.78 & 0.076 \\
Rho & -0.85 & & & \\
Sigma & 0.1008 & & & \\
\hline Source: & & & & \\
\hline
\end{tabular}

Source: own survey estimation result, $2014 / 2015$

Note: $* * *, * *$ and $*$ means significant at $1 \%, 5 \%$ and $10 \%$ probability levels respectively. 